Integrating inquiry learning and knowledge management into a flipped classroom to improve students' web programming performance in higher education

Krittawaya Thongkoo

Patcharin Panjaburee

Mahidol University, Thailand

Kannika Daungcharone

Chiang Mai University, Thailand

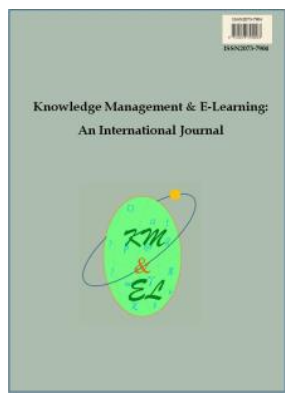

Knowledge Management \& E-Learning: An International Journal (KM\&EL) ISSN 2073-7904

Recommended citation:

Thongkoo, K., Panjaburee, P., \& Daungcharone, K. (2019). Integrating inquiry learning and knowledge management into a flipped classroom to improve students' web programming performance in higher education. Knowledge Management \& E-Learning, 11(3), 304-324. https://doi.org/10.34105/j.kmel.2019.11.016 


\title{
Integrating inquiry learning and knowledge management into a flipped classroom to improve students' web programming performance in higher education
}

\author{
Krittawaya Thongkoo \\ Institute for Innovative Learning \\ Mahidol University, Thailand \\ E-mail: krittawaya@gmail.com

\section{Patcharin Panjaburee* (6)} \\ Institute for Innovative Learning \\ Mahidol University, Thailand \\ E-mail: panjaburee_p@hotmail.com
}

\author{
Kannika Daungcharone \\ College of Arts, Media and Technology \\ Chiang Mai University, Thailand \\ E-mail: kannikadaung@gmail.com
}

*Corresponding author

\begin{abstract}
In view of the benefits of inquiry-based learning and knowledge management $(\mathrm{KM})$ in triggering students' communication and knowledge construction and the benefits of a flipped classroom in engaging student learning in- and out-of-classroom, this study proposed to integrate inquiry learning and $\mathrm{KM}$ into a flipped classroom to cultivate student webprogramming learning performance in a higher education setting. Fifty-one university students participated in a web-programming course. The students in the experimental group used the proposed approach, while those in the control group used the conventional inquiry-based flipped classroom approach. The results indicated that integrating KM and inquiry-based approach into a flipped classroom can improve students' programming skills and code comprehension and help them learn more effectively with better learning achievements.
\end{abstract}

Keywords: Inquiry-based learning; Collaborative learning; Flipped classroom; Knowledge management; Programming learning

Biographical notes: Krittawaya Thongkoo is a $\mathrm{PhD}$ candidate in Science and Technology Education, Institution for Innovative Learning, Mahidol University, Thailand and a lecturer in College of Arts, Media and Technology, Chiang Mai University, Thailand. She is interested in technology-enhanced learning, ubiquitous learning, inquiry-based learning, mobile and digital learning, learning analytics, and web-based technology.

Patcharin Panjaburee is currently an Assistant Professor of Institute for Innovative Learning, Mahidol University, Thailand. She is interested in computer-assisted testing, adaptive learning, expert systems, and digital 


\begin{abstract}
material supported learning, inquiry-based mobile learning, and web-based inquiry learning environment. More details can be found at http://patpatcharin.wixsite.com/patcharin-pan.
\end{abstract}

\begin{abstract}
Kannika Daungcharone is currently a lecturer at the Division of Modern Management and Information Technology in College of Arts, Media and Technology, Chiang Mai University, Thailand. Her research interests include technology-enhanced learning and gamification, and multimedia and information technology.
\end{abstract}

\title{
1. Introduction
}

Web-programming course provides students with critical thinking and problem-solving skills based on the principles of website design and development. It is one of skillsets for being undeniably indispensable in the $21^{\text {st }}$ century education (Kalelioğlu \& Gülbahar, 2014) and promotes rational, systematic, and creative thinking for the students. It can also be practically employed in a problem-solving process, task management, and living in current world, and can lead to a sustainable learning later in life. However, Papadopoulos and Tegos (2012) stated that some students lack of problem-solving and computational thinking skills during learning computer science course. The students have less abilities in reading, tracking, writing, and designing a simple code fragment, and difficult to understand the abstract concepts involving the role of variable position in multidimensional array, looping statement, and function. They may lose interest in learning computer programming if it leads to less learning achievement. In the past decade, learning to program with the use of computer language, especially PHP, is not an easy task. Programming lecturers were aware of the numberless problems that beset beginners (Rogalski \& Samurçay, 1990). The process of teaching and learning computer programming not only involves learners but also a set of situations where teachers deliver knowledge about the programming. That is, teaching and learning strategy may need to focus on student-centred learning activities as well as active learning to enable students communicate and construct conception of programming, such as debugging syntax error identification and analysing data flow, with peer-to-peer and peer-to-teacher interactions during the in- and the out-of-class learning process.

Among various learning environments, flipped classrooms are considered as an effective learning environment for fostering students' engagement, and supporting them in solving problems through the guidance resulting in better learning outcomes (Gilboy, Heinerichs, \& Pazzaglia, 2015; Tune, Sturek, \& Basile, 2013). Moreover, the use of computer-assisted out-of-class personal instruction and interactive in-class activities can support more interactions among peers-peers and students-teachers in the flipped classroom (Bishop \& Verleger, 2013). Therefore, the students obtain learning content from the out-of-class learning activities and then spend time in the in-class activities deepening their understanding of the content (Abeysekera \& Dawson, 2015). However, it remains challenges for conducting the flipped classroom approach, such as providing learning guidance and supporting learning responsibility (Rahman et al., 2015; Schultz, Duffield, Rasmussen, \& Wageman, 2014; McLaughlin et al., 2013; Sun, Wu, \& Lee, 2016). For example, in the out-of-class learning activities, the students may receive less opportunity for inquiring knowledge; and in the in-class learning activities, they may fail to share explanations with peers and manage their knowledge for constructing tenable concepts (Thongkoo, Panjaburee, \& Daungcharone, 2019). Accordingly, the use of 
proper teaching and learning strategy, such as inquiry-based learning and knowledge management model, for conducting the flipped classroom has become an important and challenging topic.

Therefore, in this study, a knowledge management model blended inquiry flipped classroom approach is proposed. A learning system has been implemented by basing on the proposed approach to enable students to receive open-ended question/task and basic information, explore specific phenomena based on their own understanding, share their findings, and construct their own tenable concepts, accordingly. Moreover, an experiment was conducted to evaluate the effectiveness of the proposed approach in terms of students' learning achievement, programming skills, code comprehension, and perceptions about the learning activities.

\section{Literature review}

\subsection{Flipped classroom}

Recently, several scholars have recognized flipped classroom as an effective studentcentered classroom with transforming in-class lectures for co-curricular activities, forcing students to preview course materials outside of class, reversing instruction, blending learning, or inverting classrooms (Lo, Hew, \& Chen, 2017; Bergmann \& Sams, 2012; Chen, Wang, \& Chen, 2014). Some scholars have suggested that flipped classroom is not restricted to only lectures and homework but also refers to the engagement of face-to-face interactive and higher-order activities such as problem solving, discussions, and debates (Gaughan, 2014; Bishop \& Verleger, 2013). That is, emerging technologies are utilized, and the students are required to prepare for the classes by viewing online learning materials provided by the teachers before the class began (Flumerfelt \& Green, 2013; Sahin, Cavlazoglu, \& Zeytuncu, 2015). In the flipped classroom environment, thus, there are two crucial elements, such as in-class interactive group learning activities and out-ofclass computer-based individual instruction (Bishop \& Verleger, 2013). Such that, a flipped learning classroom promoted students' levels of achievement compared to traditional lecturing (Lo \& Hwang, 2018).

To implement the flipped classroom with the use of technology, it can be divided learning activities into three stages (Kong, 2014, 2015). Firstly, in pre-class learning preparation, students are engaged in autonomous learning by using online learning platforms. Secondly, in-class learning activities, the students and teacher discuss and debate specific subject matter together. Afterward, the students are asked to present and simulate the lesson content (Chen et al., 2014; Estes, Ingram, \& Liu, 2014; Tucker, 2012); that is, the active learning strategy is aimed to improve teaching quality and learning efficiency (Baepler, Walker, \& Driessen, 2014; Demski, 2013; Sparks, 2011). Thirdly, in post-class learning consolidation, the students review materials to improve their learning outcomes. It allows them to learn out-of-class, apply knowledge gained from the in-class activities, work with peers, and receive direct feedback from teachers (Warter-Perez \& Dong, 2012). Therefore, many scholars have found that flipped classroom benefits for promoting learning performance in several areas, such as Marketing Research Courses (Shih \& Tsai, 2017), Invertebrates course (Thai, De Wever, \& Valcke, 2017), and Architectural Engineering Course (Herreid \& Schiller, 2013). Although, flipped classroom method has been utilized at various levels and suitable for programming education, in which the students could learn the theory at their own speed; teachers could concentrate in actual problems instead of repeating content knowledge in the in-class 
activities and no costly lecturing was needed (Horton \& Craig, 2015; Herala, Vanhala, Knutas, \& Ikonen, 2015). However, flipped classroom still needs mechanism to link between out-of-class and in-class learning activities.

The flipped classroom emphasizes that teachers and students occupy the different roles. It is defined as two-way interactions between teachers and students (Hassan, Abiddin, \& Yew, 2014). For the success of the flipped classroom, teachers can act as theme experts, instructional designers, and media developers for encouraging students to take active, rather than passive learning (Estes et al., 2014; Montgomery et al., 2015). Failing to complete pre-class learning preparation may affect in-class discussions and overall learning outcomes. Such that, many researchers have mentioned that student speeches, self-evaluations, peer evaluations, and group discussions can be applied into the in-class of flipped learning mode (Lai \& Hwang, 2016; Zappe et al., 2009). Consequently, the traditional face-to-face learning with e-learning platform could be used to motivate and support university student learning (Sloman, 2007).

Therefore, to realize the above goal, this study employed inquiry-based learning approach, which is one of effectiveness active learning strategies, in the flipped classroom learning system.

\subsection{Inquiry-based learning approach}

Inquiry-based learning approach is based on the principles of constructivism providing learners to construct their meaningful knowledge by acquiring information from the outside resources and developing their individual understanding through exploration, investigation, and observation in their learning environments (Feletti, 1993). Learning by doing, student-centred, and hands-on activities encourage learners to proficiently participate rather than be passive recipients of knowledge in a traditional teaching model.

Inquiry-based learning was traditionally developed in science study (Shih, Chuang, \& Huang, 2010). There are various processes related to the inquiry-based learning approach, such as questioning, designing of research, researching, analysing, summarizing, inventing, discussing, and communicating of explanation ( $\mathrm{Wu} \& \mathrm{Hsieh}$, 2006). The investigation of knowledge is a practice employed by scientists to study and explain natural phenomena. This practice is based on evidence and reason. In other words, it is a process in which students systematically research for explanations and answers of occurrences at their interests. In classes of science learning, the teachers according to contexts of delivery, students, school, and available sources can customize the inquiry process. They support students in investigations of phenomena and induce the students to establish correct scientific understanding (Hogan \& Berkowitz, 2000). Inquiry-based learning is applied when teachers aim to coach their students to practice systematic problem solving and, ultimately, to acquire problem-solving skills, and to understand relevancy of related information on which they can build a specific knowledge themselves. The contents must lead to topical issues/problems. Inquiry process is, therefore, a learning process allowing students to establish their new bodies of knowledge by themselves through thinking and practicing processes. Additionally, researchers revealed that technology-integrated inquiry-based learning approach effectively supported the students' web-programming learning achievement and promoted positive perceptions toward learning activities (Thongkoo et al., 2017, 2019). However, inquirybased learning, which is used in traditional classrooms or is integrated within computerbased learning, might not suitable to motivate students' explanations and constructions 
tenable concepts (Chang, Chang, \& Shih, 2016). Accordingly, this study attempted to reduce the previous ill-structured inquiry learning implementations.

\subsection{Knowledge management}

Knowledge is the most valuable resource in the global society. Knowledge is also vital in building of economic advantages within the knowledge-based economy (Salem, 2014). It is necessary to learn, study, and apply knowledge in order to a sustainable development (Omotayo, 2015). Knowledge must be built from the development of thoughts or knowledge management. There are two types of knowledge (i.e., explicit knowledge and tacit knowledge) (Nonaka \& Toyama, 2003). The first one can be collected and transmitted through various channels such as writings, theories, manuals, documents, regulations, operation manuals, and media storage. The second one can be acquired through experiences and talents or personal instinct of persons to comprehend. It is not easily communicable either in words or in writings. The examples of this knowledge are working skills, experiences, and concepts. For this reason, it is very crucial to manage those kinds of knowledge in a systematic and logical way as called as "knowledge management (KM)". In other words, $\mathrm{KM}$ is a process commencing from identifying of existing knowledge within the organization, gathering such knowledge from the members of the organization, categorizing all the knowledge, disseminating the body of knowledge, exchanging of knowledge and creating ambiance (Alavi \& Leidner, 1999). It facilitates learning experience and eventually results in fruitful application of knowledge to achieve organization's objectives. Integration of KM and learning has been widely used to support knowledge creation in a systematic way (Pattnaya, 2017). In higher education, $\mathrm{KM}$ is an important factor in creating, acquiring, disseminating, and leveraging knowledge for attaining competitive advantage and institution's objectives through collaborative learning and student-teachers interaction (Fauzi, Christine, \& Ramayah, 2018; Girard, Yerby, \& Floyd, 2016).

Interestingly, Nonaka and Takeuchi (1995) have invented SECI model as a knowledge management framework determining the relationships between explicit and tacit knowledge. SECI model creates new knowledge in a never-ending spiral form as learning process occurs constantly. There are four processes of SECI model: Socialization, Externalization, Combination, and Internalization. Socialization refers to a social interaction, where experienced individuals transfer their knowledge to another individual or a group of individuals directly through imitation and practice. This process is a form of mutual knowledge transfer and does not require explicit or written means; therefore, it requires face-to-face interaction or on-field practice for instance knowledge that passed on from supervisors to trainees. Externalization is recognized as individuals attempt to transform tacit knowledge into explicit knowledge by the use of metaphors, comparisons, concepts, principles, hypothesis, or models. Combination is defined that individuals may exchange and combine explicit knowledge with the use of means such as documentation, computerized system, and technology in communications. In recent years, computers and ICT are most dominant means in the combination process of explicit knowledge. Those could be high benefits to the organization. Internalization, in which knowledge is learnt from the process of socialization, externalization, and combination, will become a part of individuals' new innovative knowledge. It is considered crystalized knowledge arose from individual's learning process, for example, new skillsets accumulated through years of working experience. Many scholars have applied the SECI model in many ways. For example, Kassem, Hammami, and Alhousary (2015) revealed that there were significant and positive relationships between the e-Learning environment and SECI model. E-Learning environment required students to share, construct, and 
utilize knowledge through socialization, externalization, combination, and internalization. Rice and Rice (2005) applied SECI model for accumulating knowledge and processing learning in multi-organisational projects.

According to the literature reviews, in this study, a KM model blended inquiry flipped classroom approach was proposed for triggering and engaging students' communicating and constructing knowledge systemically in web-programming learning. Moreover, an experiment was conducted involving university students in a webprogramming course by investigate the following research questions:

1) Can the KM model blended inquiry flipped classroom approach improve the students' learning performance in terms of learning achievement, programming skills, and code comprehension in comparison with the conventional inquiry flipped classroom?

2) Can the KM model blended inquiry flipped classroom approach improve the students' perceptions toward the classroom in comparison with the conventional inquiry flipped classroom?

\section{Integrating inquiry learning and $\mathrm{KM}$ into a flipped classroom}

To trigger students for managing web programming knowledge in a systematic and logical way, a KM model blended inquiry learning system was developed for supporting the flipped classroom learning activities. In this study, the system was constructed with HTML5, JavaScript, PHP, Google Cloud Datastore as a database, Laravel as a website framework and Firebase framework for real-time working. There are several reasons for choosing the online system in this study. Firstly, it is good enough for in- and out-of-class. Secondly, the developed learning system with Laravel can be executed on many devices such as personal computer, laptop, smartphone, and tablet. Finally, teacher can track the students' learning activities during their learning with the system.

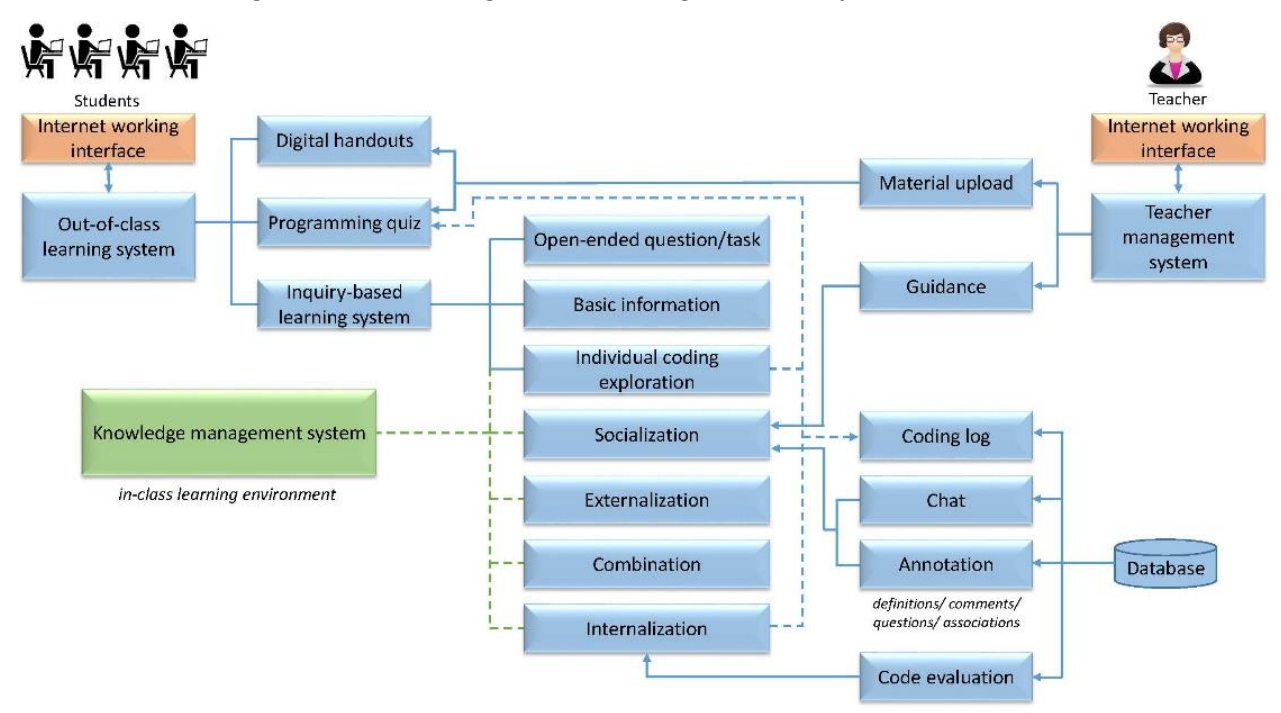

Fig. 1. The proposed flipped classroom environment 
The KM model blended inquiry learning system consists of a teacher management system, an out-of-class learning system, an inquiry-based learning system, a knowledge management system, and a database as shown in Fig. 1. The teacher management system allows teacher to upload learning materials related to PHP programming for students and to provide guidance based on students' coding program. The out-of-class learning system consists of the digital handouts and some web programming quizzes provided by the teacher; the students are asked to read the handouts and take the quizzes before starting the learning activities. The inquiry-based learning system is a platform on which the students can receive question/task and basic information and are asked to explore PHP programming language concept by coding program individually. Moreover, the students can communicate and discuss about the coding with peers before starting the in-class activities. The knowledge management system is another platform on which the students can check and evaluate their web programming knowledge in a systematic and logical way. Finally, the database not only records the students' coding logs, but also provides them with live chat and annotation tools.

In this study, the PHP function unit of web-programming course is used to demonstrate the effectiveness of the KM model blended inquiry flipped classroom approach. The students are asked to learn the principle of writing PHP Function, using PHP built-in function, and creating PHP user-defined function with specific command. Moreover, they are assigned to self-answer for two questions and then find out the group answer. To further explain the KM model blended inquiry flipped classroom approach for supporting PHP learning achievement and web programming skills (i.e., PHP programming skills and code comprehension), Fig. 2 shows the learning flow of the students' learning process.

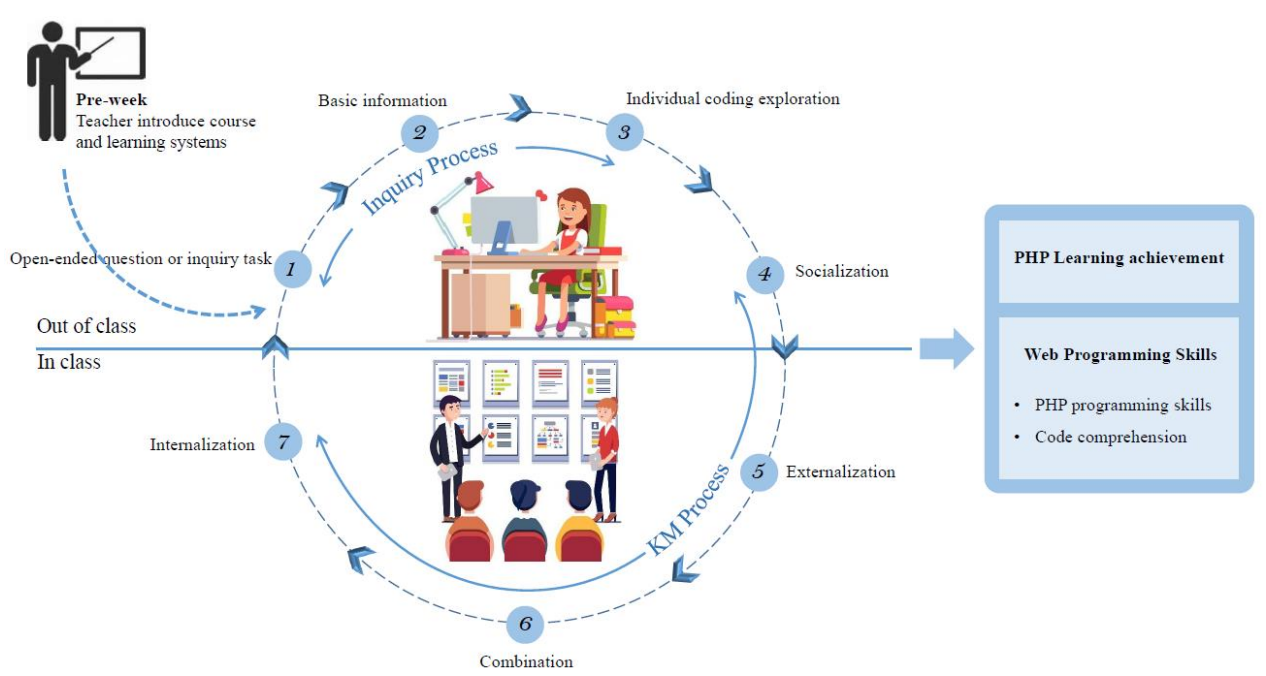

Fig. 2. Learning procedure using the proposed approach

At the beginning of the learning unit, the teacher introduces learning objectives and course outline of the PHP function unit, and then explains the learning modes of the out-of-class learning system, the inquiry-based learning system, and the knowledge management system. Once the students understand the learning modes, they are asked to identify themselves with username and password for logging into the learning system. This could help the teacher to identify and monitor each student's learning progression. After that, the students are allowed to learn in the out-of-class learning system; in this 
system, they can read digital handouts and take programming quizzes wherever they are, and their answers will be recorded in the database. After submitting the quiz answers into the system, they can access the inquiry-based learning system (i.e., open-ended question or inquiry task, basic information, individual coding exploration modes) and a part of the knowledge management system (i.e., socialization mode). They are before starting the inclass activities in the rest learning mode of the knowledge management system (i.e., externalization, combination, and internalization modes).

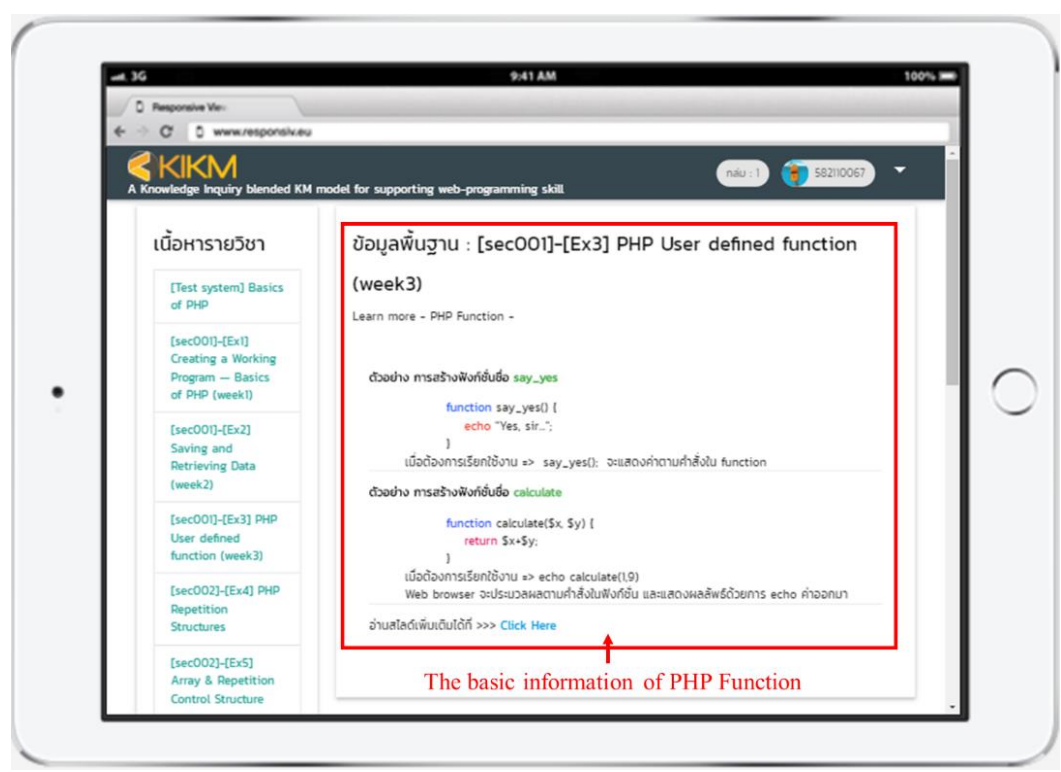

Fig. 3. Illustrate example of the basic information-learning mode

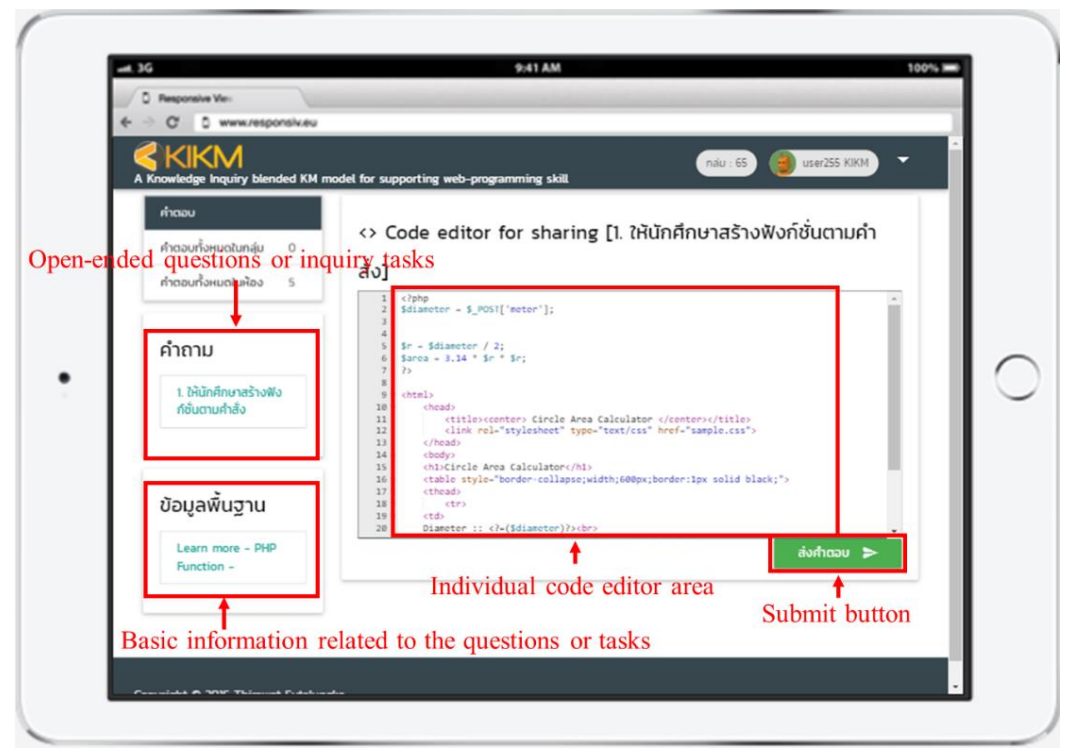

Fig. 4. Individual code editor screen for exploring PHP programming language in the individual coding exploration mode 
In the open-ended question or inquiry task mode, the system provides two tasks of the web-programming content for encouraging the students to solve the problem/task by using PHP programming language. For example, the students receive problem as follows: Create your own PHP function to calculate a social security deduction of $7 \%$ of your salary (Social Security deduction $=7 \%$ but not more than 750 Baht. Along with the problem/task, in the basic information mode, the students can self-study the related information about the PHP Function content as shown in Fig. 3. This basic information will allow them to apply their knowledge to solve the given problem/task. Afterwards, in the individual coding exploration mode, a student is asked to start programming in the specified code editor area to explore PHP programming language corresponding to the open-ended question/inquiry task as shown in Fig. 4. The student can also see additional information related to the given task during exploring.

When finishing coding the PHP program, the student will be asked to submit his/her program to the group computer-programming session for further discussion wherever they are. That is, the student will be automatically moved into the socialization mode of the knowledge management system. In the socialization mode, each student can see computer programming provided by other three members in each group as shown in Fig. 5.

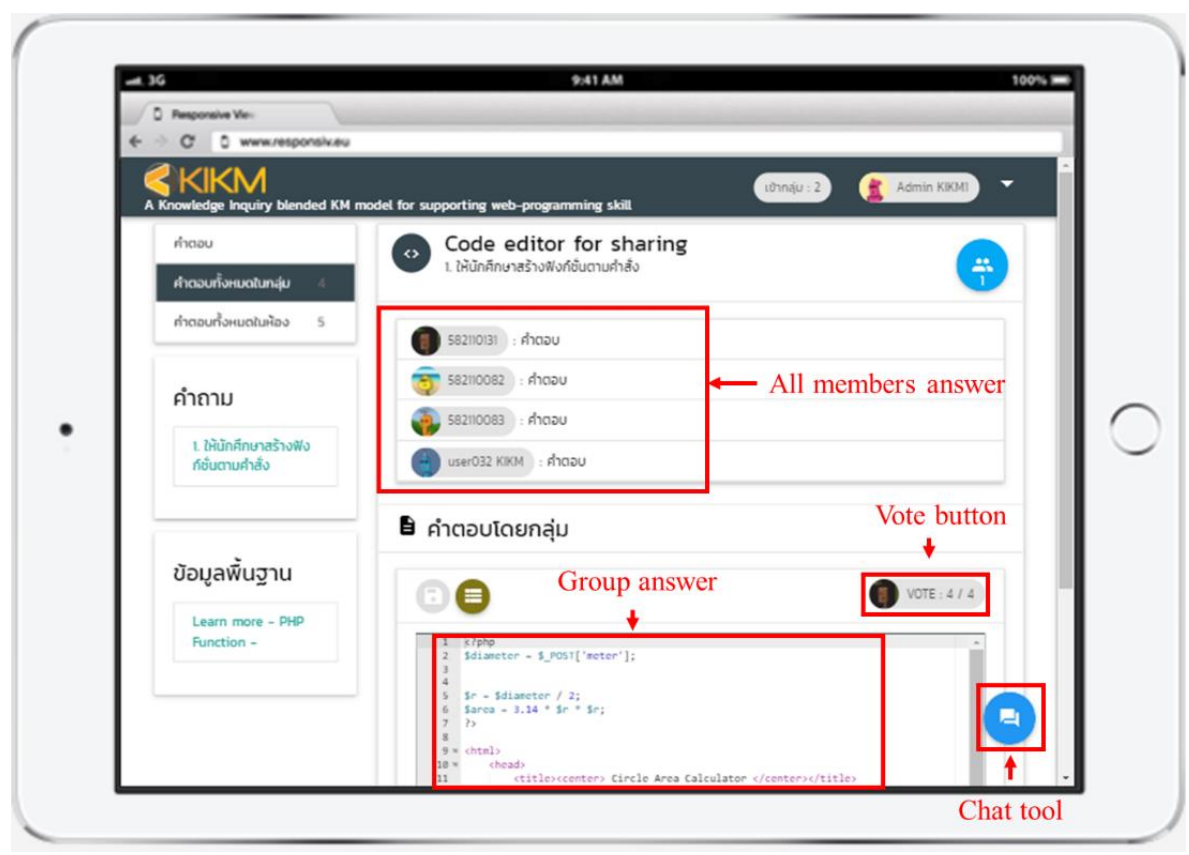

Fig. 5. Illustrate group PHP programming screen of the socialization mode

Moreover, Fig. 6 shows that the socialization mode allows the students to use annotation tools to inquire or give the recommendation into the answer/computer programming to peers. The annotation tools consist of definitions, comments, questions, and associations. Moreover, the students can use the chat room in order to communicate and discuss about the strengths and weaknesses of their own and peers' programming until they find the best programming of the group. Such that, tacit knowledge about PHP functions of each student could be acquired through discussion. That is, they are finished the out-of-class learning activities and ready for participating in the in-class learning activities. 


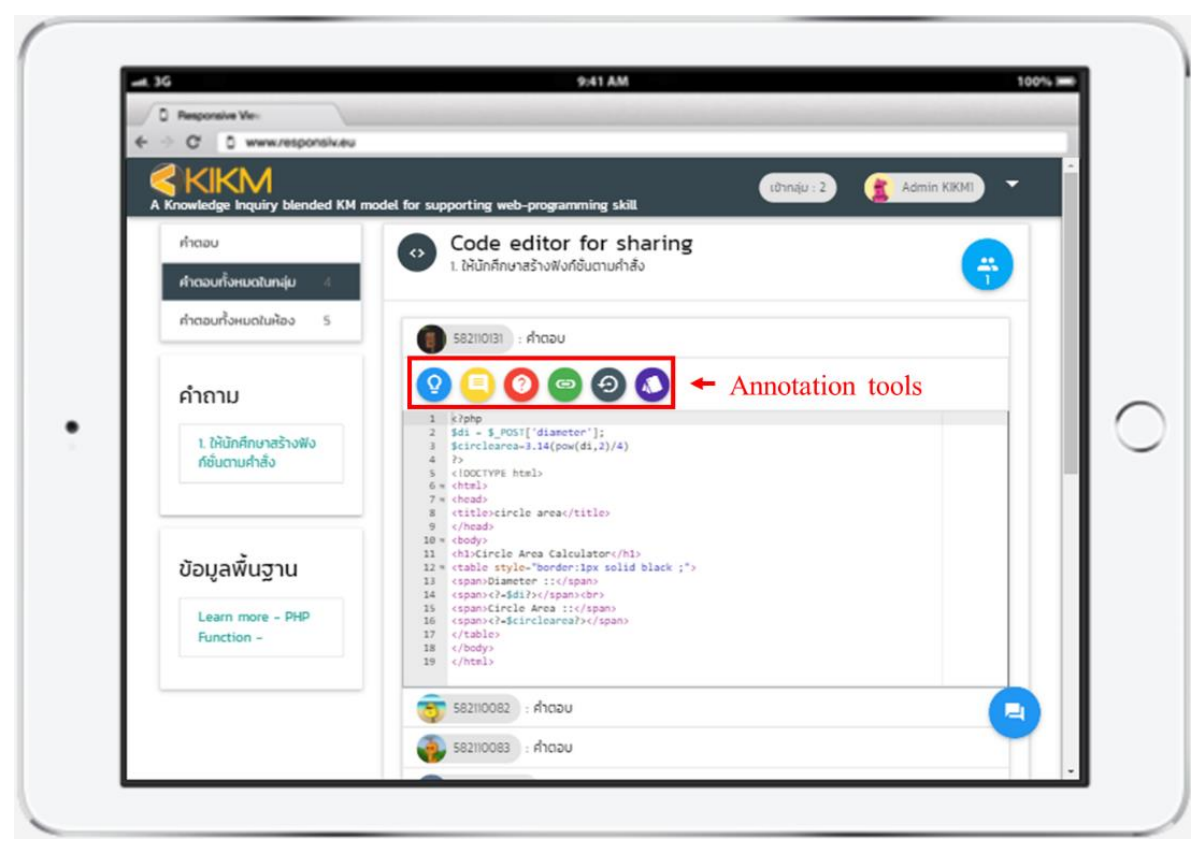

Fig. 6. Annotation tools and chat live in the socialization mode

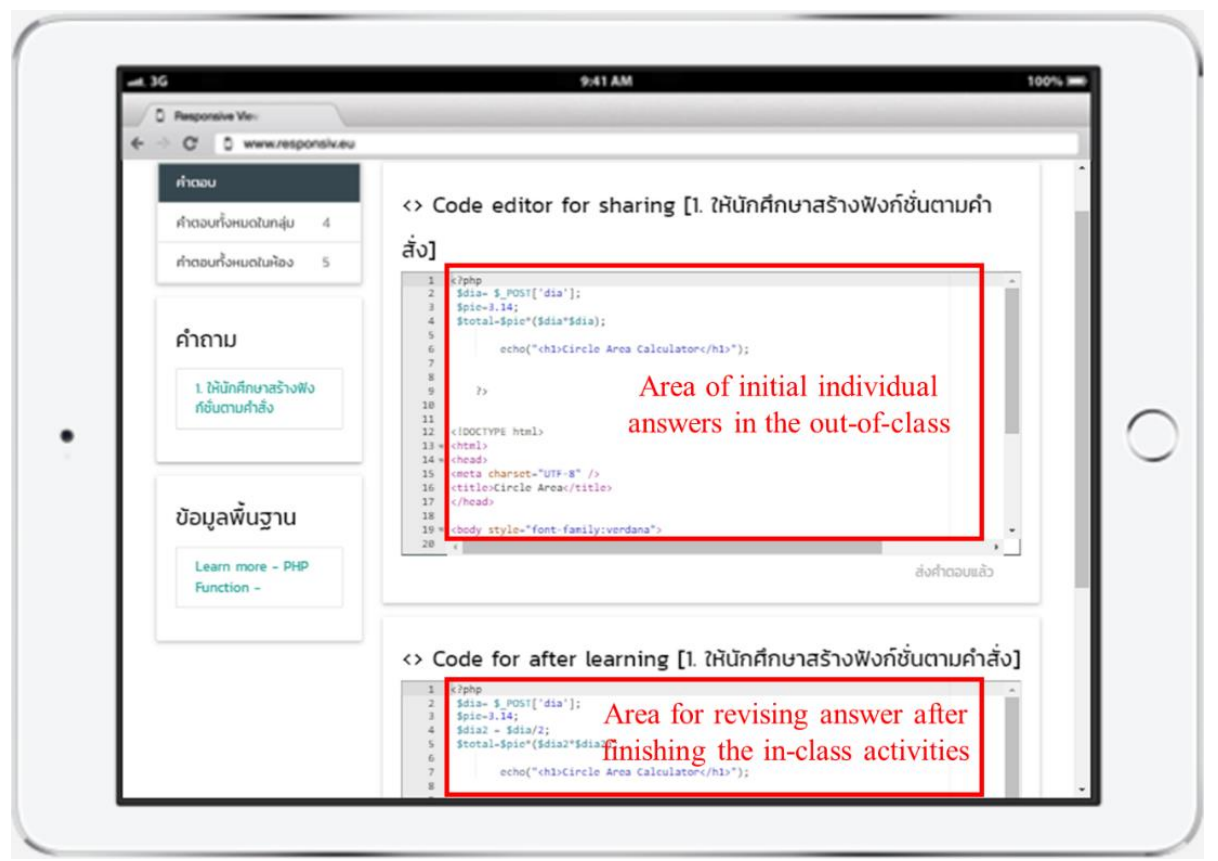

Fig. 7. Revising code editor area of each student in the internalization mode

In the in-class learning environment, the learning activity is started with the externalization mode, where the teacher showed and compared PHP programming of every group to the class. The teacher asked the students to write down strengths, weaknesses, and limitations of each programming. Such that, the students' tacit 
knowledge created from the socialization mode is made explicit by using PHP programming comparisons and PHP principles; it might help the students understand various methods for coding in the same problem/task. After that, the combination mode starts to allow the students to exchange and combine explicit knowledge with the other resources such as course documentation, computerized system, and other information and technologies in communications concerning PHP programming language. Finally, in the internalization mode, each student receives additional recommendations of PHP programming corresponding to the question/task. The system provides an opportunity for each student to revise his/her PHP programming once again as shown in Fig. 7. It means that this learning mode allows each student to construct his/her knowledge of PHP programming language by applying knowledge gained from the previous modes.

\section{Research methodology}

\subsection{Participants}

In this study, the participants were two classes of second year university students who enrolled in the web-programming course in a university. The number of students in each class was assigned by course registration of the university. A total of 51 students participated in this study. The age of the students was $19-20$ years old. One class was randomly assigned to be the experimental group, and another was the control group. The experimental group, including 29 students, learned with the KM model blended inquiry flipped classroom approach. On the other hand, the control group, including 22 students, learned with the inquiry flipped classroom; that is, the teachers played the main role in encouraging students to conduct peer explanations and construct their own PHP function knowledge without the KM process.

\subsection{Measuring tools}

The instruments of this study included the pre-test, post-test, the PHP programming skill rubric-score, the code comprehension rubric-score, and the questionnaire of perceptions toward the classroom.

The pre-test and post-test were developed by four experienced teachers in teaching the web-programming course. Each test consisted of 15 multiple-choice items, with one point awarded for each correct answer; therefore, a total score of each test was 15. The pre-test aimed to evaluate the students' prior knowledge of the PHP function content covering PHP user defined function and PHP built-in function, while the post-test aimed to evaluate the PHP programming learning achievement of the students after completing learning activities. The questions of pre-test and post-test are different, but they are the same content of PHP programming language. The Kuder-Richardson Formula 20 of the pre-test and post-test were 0.75 , showing an acceptable reliability in internal consistency.

The PHP programming skill rubric-score consisted of three skills with a threepoint Likert scale ranging from low- to high-performance, as shown in Appendix I. The first skill describes the ability in PHP programming language planning and solving problems from given proposition (S1). A student shows high performance when he/she knows the PHP statement that must be used and can define variables to each set of command. The second skill describes the capability of student ability to understand PHP programming language structures and make the program output correctly (S2), that is, a 
student shows high performance when he/she is able to debug both command line and PHP functions. The third skill describes the capability to give suggestion in writing PHP programming language (S3), that is, a student shows high performance when he/she is able to suggest writing PHP for creating a set of commands in every point.

The code comprehension rubric-score consisted of three skills with a three-point Likert scale ranging from low- to high-comprehension. The first comprehension describes the understanding of PHP programming language structures $(\mathrm{C} 1)$, that is, a student shows high comprehension when he/she understands the structures, command line writing, and PHP programming language. The second comprehension describes the understanding of PHP function code (C2), that is, a student shows high comprehension when he/she understands the PHP function code and can choose a set of commands. The third comprehension describes the ability to adapt the knowledge (C3), that is, a student shows high comprehension when he/she is able to adapt the knowledge into all practical learning.

The questionnaire of perceptions toward learning activity was adopted from Liaw (2008). It consisted of 16 items with a five-point Likert scale ranging from strongly disagree to strongly agree, including 6 for perceived usefulness, 5 for perceived ease of use, 3 for attitudes, and 2 for intention to use. The perceived usefulness describes the degree to which a student believes that the learning activities or services provided in the learning approach are useful for improving his/her learning performance. The perceived ease of use presents the degree to how effortless he or she perceives that using the learning system will be free of cognitive effort. The attitudes describe the degree to which an individual's attitudes toward the learning approach. The intention to use presents the degree to which the intent of using the learning activities. The Cronbach's alpha values of the four dimensions were $0.81,0.88,0.70$, and 0.86 , respectively, and the total Cronbach's alpha value of the questionnaire was 0.89 , implying that it is reliable.

\subsection{Experimental procedure}

The experiment was conducted on the PHP function unit of a web-programming course, which aims to enhance the abilities of students' website design and development. Before conducting the experiment, both groups of students took the pre-test in order to evaluate their prior knowledge of PHP function (30 minutes). Following that, the teacher introduced the course syllabus, learning activity, and learning system (30 minutes).

During the out-of-class learning activities, the students in experimental group received the developed online-learning platform including inquiry-based learning mechanism (i.e., open-ended question or inquiry task, basic information, individual coding exploration), individual and in-group code editor areas, annotation tools, and chat live with support of socialization mode of KM process. They were asked to share their tacit knowledge about PHP programming with peers through an online-learning system. The students in the control group received an online-learning system with only support of inquiry-based learning mechanism. Then, in-class activities, the two groups were taught about PHP function unit by the same teacher and performed the code discussion (120 minutes). At here, to conduct peer explanations-discussion and construct PHP function knowledge, the students in experimental group received the developed online-learning platform including annotation tools and chat live with support of externalization, combination, and internalization modes of KM process. In the same time, those in control group received only teacher's support without the KM process. 
After finishing whole-class discussion, each student is asked to revise his/her answer/coding once again (30 minutes). At here, scoring rubrics were used to evaluate students' performance in programming skills and code comprehension. After finishing learning activities, the students took the post-test and completed the questionnaire to elicit their perceptions toward the classroom (40 minutes).

\section{Experimental results}

In this study, students' learning performance in terms of PHP learning achievement, PHP programming skill, and code comprehension, and their perceptions about the classroom were tested by using the IBM SPSS.

\subsection{Analysis of learning performance}

\subsubsection{Learning achievement}

The one-way analysis of covariance (ANCOVA) was employed to examine students' learning achievements on the PHP programming topic in the two groups of students. In this analysis, the pre-test was a covariate variable and the Levene's test of determining homogeneity of variance was not violated $(F(1,49)=1.099, p>0.05)$. It indicates that the assumption is reasonable to perform the one-way ANCOVA for interpreting the relationships between the students' prior knowledge (pre-test) and their learning achievement (post-test).

Table 1

The one-way ANCOVA results of the post-test scores of the two groups

\begin{tabular}{lcccccc}
\hline \multicolumn{1}{c}{ Group } & $\mathrm{N}$ & Mean & SD & $\begin{array}{c}\text { Adjusted } \\
\text { mean }\end{array}$ & SE & $F$ \\
\hline $\begin{array}{l}\text { Experimental } \\
\text { group }\end{array}$ & 29 & 9.65 & 1.29 & 9.876 & 0.238 & $48.083^{*}$ \\
$\begin{array}{l}\text { Control group } \\
\text { Note. }{ }^{*} p<0.05\end{array}$ & 22 & 7.23 & 1.60 & 7.345 & 0.274 & \\
\hline
\end{tabular}

Table 1 shows the results of the learning achievement according to the post-tests of the two groups. The means and standard derivation were 7.23 and 1.60 for the control group, and 9.65 and 1.29 for the experimental group. It was found that the post-test scores of the two groups were significantly different $(F(1,48)=48.083, p<0.05)$. The post-test score of the experimental group was significantly higher than that of the control group. This implies that the KM model blended inquiry flipped classroom benefited the students more than the conventional inquiry flipped classroom.

\subsubsection{PHP programming skills}

To determine the students' PHP programming skills in the experimental and the control groups. The Box's M test of equality of covariance matrices was performed, indicating that the equality of covariance matrices was not violated with $F_{(1,49)}=0.899$ and $p>0.05$. Therefore, one-way multivariate analysis of variance (MANOVA) test can be performed. It was found that there was a statistically significant difference in programming skills between the two groups $\left(F_{(1,49)}=7.815, p<.0005\right.$; Wilk's $\Lambda=0.667$, partial $\left.\eta^{2}=0.333\right)$. 
Table 2

The descriptive data of the programming skills of two groups

\begin{tabular}{cllcccc}
\hline $\begin{array}{c}\text { PHP } \\
\text { programming } \\
\text { skill }\end{array}$ & \multicolumn{1}{c}{ Group } & N & Mean & SD & $P$ & $\eta^{2}$ \\
\hline S1 & Control group & 22 & 8.546 & 0.596 & 0.176 & 0.037 \\
& Experimental group & 29 & 8.759 & 0.511 & & \\
S2 & Control group & 22 & 7.500 & 0.598 & $0.000^{*}$ & 0.229 \\
& Experimental group & 29 & 8.345 & 0.897 & & \\
S3 & Control group & 22 & 5.727 & 0.883 & $0.014^{*}$ & 0.116 \\
& Experimental group & 29 & 5.103 & 0.860 & & \\
\hline
\end{tabular}

Note. ${ }^{*} p<0.05$

Table 2 shows that there was no significant difference of ability in PHP programming language planning and solving problems from given proposition (S1) between the students who learned with the KM model blended inquiry flipped classroom $($ Mean $=8.759, \mathrm{SD}=0.511)$ and the conventional inquiry flipped classroom (Mean $=$ $8.546, \mathrm{SD}=0.596)$. In addition, the students who learned with the KM model blended inquiry flipped classroom (Mean $=8.345, \mathrm{SD}=0.897$ ) had ability to understand the structure of PHP programming and make the program output correctly (S2) more than those who learned with the conventional inquiry flipped classroom (Mean $=7.500, \mathrm{SD}=$ 0.598), significantly. While, the students who learned with the conventional inquiry flipped classroom (Mean $=5.727, \mathrm{SD}=0.883$ ) had ability to give the coding guidance to the others (S3) more than those who learned with the KM model blended inquiry flipped classroom $($ Mean $=5.103, \mathrm{SD}=0.860)$, significantly.

\subsubsection{Code comprehension}

Table 3

The Mann-Whitney U test results of code comprehension scores of the two groups

\begin{tabular}{clccccc}
\hline $\begin{array}{c}\text { Code } \\
\text { comprehension } \\
\text { dimension }\end{array}$ & \multicolumn{1}{c}{ Group } & N & Mean & SD & $Z$ & $p$ \\
\hline C1 & Control group & 22 & 8.182 & 0.907 & 2.568 & $0.005^{*}$ \\
& Experimental group & 29 & 8.724 & 0.528 & & \\
C2 & Control group & 22 & 6.682 & 0.716 & 5.949 & $0.000^{*}$ \\
& Experimental group & 29 & 8.690 & 0.604 & & \\
C3 & Control group & 22 & 6.727 & 0.935 & 5.640 & $0.000^{*}$ \\
& Experimental group & 29 & 8.655 & 0.670 & & \\
\hline
\end{tabular}

Note. ${ }^{*} p<0.05$

Before comparing code comprehension scores of the students between the two groups, the Box's M test of equality of covariance matrices was performed and found that the equality of covariance matrices was violated with $F_{(1,49)}=6.381$ and $p<0.05$. Therefore, one-way multivariate analysis of variance (MANOVA) test cannot be performed. In the same time, it was found that the code comprehension scores are not normally distributed; parametric statistical tests could not be performed. Consequently, the Mann-Whitney U 
test (non-parametric) was used to compare differences of code comprehension scores between two groups. Table 3 shows that the students in the experimental group had higher code comprehension scores than those in the control group, significantly. These results imply that the KM model blended inquiry flipped classroom can more significantly support students' PHP code comprehension than the conventional inquiry flipped classroom.

\subsection{Learner perceptions}

In order to investigate students' perceptions about the classroom, Mann-Whitney U test was conducted to compare the perception ratings of the students between the two groups. Table 4 shows that perceptions about learning activities of the experimental group were significantly higher than those of the control group. It indicates that the students, who followed the KM model blended inquiry flipped classroom, were more significantly satisfied and accepted than those who followed the conventional inquiry flipped classroom. They felt that the KM model blended inquiry flipped classroom was a useful learning activity, easy and convenient to follow, supported them to complete the learning tasks during receiving proper learning material of PHP Function, and accepted to use such learning approach for supporting their learning in other topics.

Table 4

The Mann-Whitney $\mathrm{U}$ test results of perception ratings of the two groups

\begin{tabular}{lllllll}
\hline \multicolumn{1}{c}{ Dimension } & \multicolumn{1}{c}{ Group } & N & Mean & SD & $Z$ & $p$ \\
\hline Perceived & Control group & 22 & 20.273 & 3.225 & \multirow{2}{*}{2.051} & $0.020^{*}$ \\
Usefulness & Experimental group & 29 & 22.103 & 2.498 & & \\
Perceived & Control group & 22 & 16.046 & 2.984 & & \\
Ease of Use & Experimental group & 29 & 20.207 & 1.473 & 4.666 & $0.000^{*}$ \\
& Control group & 22 & 10.227 & 1.602 & & \\
Attitude & Experimental group & 29 & 12.448 & 1.021 & 4.775 & $0.000^{*}$ \\
Intention to & Control group & 22 & 6.591 & 1.054 & & \\
Use & Experimental group & 29 & 8.793 & 0.774 & 5.481 & $0.000^{*}$ \\
\hline Note. ${ }^{*} p<0.05$ & & & & & &
\end{tabular}

Table 5

The Pearson's correlation coefficient of students' perceptions among the four dimensions of questionnaire

\begin{tabular}{lcccc}
\hline \multicolumn{1}{c}{ Dimension } & PU & POU & AT & IU \\
\hline Perceived Usefulness (PU) & 1 & & & \\
Perceived Ease of Use (POU) & $0.406^{*}$ & 1 & & \\
Attitude (AT) & 0.260 & $0.566^{*}$ & 1 & \\
Intention to Use (IU) & $0.370^{*}$ & $0.732^{*}$ & $0.637^{*}$ & 1 \\
\hline Note. ${ }^{*} p<0.01$ & & & &
\end{tabular}

To further understanding how each dimension of perceptions about the KM model blended inquiry flipped classroom correlated to each other, the relationships among the four dimensions of perceptions were verified. Pearson's coefficient between each pair of dimensions was calculated as shown in Table 5. It was found that there were significantly 
positive relationships among the four dimensions. This implies that the students were more likely to continue using the KM model blended inquiry flipped classroom in the future because they felt that the learning activities or services provided in the classroom were useful for improving his/her understanding and learning performance.

\section{Discussion and conclusions}

Recently, the applications of knowledge management model and inquiry-based learning approach and implementation of the flipped classroom have been regarded as necessary elements for higher education to acquire appropriate skills, abilities, and competences in the era of knowledge economics and information technology. Especially, technologyintegrated flipped classroom has benefited students' learning performance (Thai et al., 2017; Lai \& Hwang, 2016; Yilmaz, 2017; Baepler et al., 2014). In order to enhance the effectiveness of the flipped classroom, this study developed a KM model blended inquiry flipped classroom approach for assisting students' out-of-class learning and improving the quality of the in-class interaction with peers-peers and students-teachers. It led to provide meaningful principles for coding a PHP programming.

An experiment was conducted in undergraduate students to evaluate the effectiveness of the proposed learning approach. The students in the experimental group learned with the KM model blended inquiry flipped learning classroom, while those in the control group participated in the conventional inquiry flipped learning classroom. The experimental results revealed that the proposed classroom significantly benefited the students' learning achievement, programming skill in ability to understand the structure of PHP programming and make the program output correctly, and code comprehension. These findings provide evidence that the enhanced inquiry-based learning strategy with the knowledge management model benefits students in terms of the conscious construction of knowledge and the use of effective learning strategies (Thongkoo et al., 2017). Therefore, the KM model blended inquiry flipped classroom approach of this study provides a strong learning mechanism by which students can use annotation tool during in-group learning activities and evaluate the most appropriate PHP coding strategies at the in- and the out-of-class. This result also conforms to the theory proposed by Wang (2017) that the integration of such learning strategy into the courses improved the students' learning achievements. Additionally, this study allowed the students to experience active learning and receive the suggestion during individual and group learning activities, which enhanced their knowledge (Tatachar, Li, Gibson, \& Kominski, 2016).

In conclusion, the major contribution of this study is to evidence that integrating the knowledge management-inquiry-based learning strategy into flipped learning improves students' web-programming performance. Because the students can explore PHP coding corresponding to inquiry tasks, use annotation tools, and chat live at the outof-class, and can communicate and construct PHP knowledge with the systematic way of knowledge management model at the in-class. Thus, it is further improving their positive perceptions about the proposed classroom.

On the other hand, it remains a challenge to develop supporting tool for promoting students' programming skill in ability to give the coding guidance to the others when implementing the KM model blended inquiry flipped classroom. In addition, it takes time for teachers to prepare proper course content without supporting tool; therefore, it is important to develop the tools to facilitate teachers in the future study. It would also be interesting to collect and analyse data in multiple ways, such as students' 
behaviours in each learning unit, learning interest, learning sustainability when the KM model blended inquiry flipped classroom approach is implementing.

\section{ORCII}

Krittawaya Thongkoo (D) https://orcid.org/0000-0003-2167-658X

Patcharin Panjaburee (iD https://orcid.org/0000-0002-9781-8743

Kannika Daungcharone (D) https://orcid.org/0000-0002-4108-2087

\section{References}

Abeysekera, L., \& Dawson, P. (2015). Motivation and cognitive load in the flipped classroom: Definition, rationale and a call for research. Higher Education Research \& Development, 34(1), 1-14.

Alavi, M., \& Leidner. D. E. (1999). Knowledge management systems: Issues, challenges, and benefits. Communications of the Associaton for Information Systems, 1(1): 7.

Baepler, P., Walker, J. D., \& Driessen, M. (2014). It's not about seat time: Blending, flipping, and efficiency in active learning classrooms. Computers \& Education, 78, 227-236.

Bergmann, J., \& Sams, A. (2012). Flip your classroom: Reach every student in every class every day. Washington DC: International Society for Technology in Education.

Bishop, J. L., \& Verleger, M. A. (2013). The flipped classroom: A survey of the research. In Proceedings of the 120th ASEE National Conference and Exposition (Paper ID 6219). Washington, DC: American Society for Engineering Education.

Chang, C., Chang, C. K., \& Shih, J. L. (2016). Motivational strategies in a mobile inquiry-based language learning setting. System, 59, 100-115.

Chen, Y., Wang, Y., \& Chen, N. S. (2014). Is FLIP enough? Or should we use the FLIPPED model instead? Computers \& Education, 79, 16-27.

Demski, J. (2013). 6 expert tips for flipping the classroom. Campus Technology, 26(5), $32-37$.

Estes. M. D., Ingram, R., \& Liu, J. C. (2014). A review of flipped classroom research, practice, and technologies. International HETL Review, 4: 7.

Fauzi, M. A., Tan, C. N. L., \& Ramayah, T. (2018). Knowledge sharing intention at Malaysian higher learning institutions: The academics' viewpoint. Knowledge Management \& E-Learning, 10(2), 163-176.

Feletti, G. (1993). Inquiry based and problem based learning: How similar are these approaches to nursing and medical education? Higher Education Research and Development, 12(2), 143-156.

Flumerfelt, S., \& Green, G. (2013). Using lean in the flipped classroom for at risk students. Educational Technology \& Society, 16(1), 356-366.

Gaughan, J. E. (2014). The flipped classroom in world history. The History Teacher, 47(2), 221-244.

Gilboy, M. B., Heinerichs, S., \& Pazzaglia, G. (2015). Enhancing student engagement using the flipped classroom. Journal of Nutrition Education and Behavior, 47(1), $109-114$.

Girard, J. P., Yerby, J., \& Floyd, K. (2016). Knowledge retention in capstone experiences: An analysis of online and face-to-face courses. Knowledge Management \& ELearning, 8(4), 528-539.

Hassan, A., Abiddin, N. Z., \& Yew, S. K. (2014). The philosophy of learning and 
listening in traditional classroom and online learning approaches. Higher Education Studies, 4(2), 19-28.

Herala, A., Vanhala, E., Knutas, A., \& Ikonen, J. (2015). Teaching programming with flipped classroom method: A study from two programming courses. In Proceedings of the 15th Koli Calling Conference on Computing Education Research (pp. 165-166). Koli, Finland.

Herreid, C. F., \& Schiller, N. A. (2013). Case studies and the flipped classroom. Journal of College Science Teaching, 42(5), 62-66.

Hogan, K., \& Berkowitz, A. R. (2000). Teachers are inquiry learners. Journal of Science Teacher Education, 11(1), 1-25.

Horton, D., \& Craig, M. (2015). Drop, fail, pass, continue: Persistence in CS1 and beyond in traditional and inverted delivery. In Proceedings of the 46th ACM Technical Symposium on Computer Science Education (pp. 235-240).

Kalelioğlu, F., \& Gülbahar, Y. (2014). The effect of instructional techniques on critical thinking and critical thinking dispositions in online discussion. Educational Technology \& Society, 17(1), 248-258.

Kassem, S., Hammami, S., \& Alhousary, T. (2015). Applying SECI model to encourage knowledge creation in elearning environment. International Journal of Economic Research, 12(4), 1601-1611.

Kong, S. C. (2014). Developing information literacy and critical thinking skills through domain knowledge learning in digital classrooms: An experience of practicing flipped classroom strategy. Computers \& Education, 78, 160-173.

Kong, S. C. (2015). An experience of a three-year study on the development of critical thinking skills in flipped secondary classrooms with pedagogical and technological support. Computers \& Education, 89, 16-31.

Lai, C. L., \& Hwang, G. J. (2016). A self-regulated flipped classroom approach to improving students' learning performance in a mathematics course. Computers \& Education, 100, 126-140.

Liaw, S.-S. (2008). Investigating students' perceived satisfaction, behavioral intention, and effectiveness of e-learning: A case study of the blackboard system. Computers \& Education, 51(2), 864-873.

Lo, C. K., Hew, K. F., \& Chen, G. (2017). Toward a set of design principles for mathematics flipped classroom: A synthesis of research in mathematics education. Educational Research Review, 22, 50-73.

Lo, C. K. \& Hwang, G. J. (2018). How to advance our understanding of flipped learning: Directions and a descriptive framework for future research. Knowledge Management \& E-Learning, 10(4), 441-454.

McLaughlin, J. E., Griffin, L. M., Esserman, D. A., Davidson, C. A., Glatt, D. M., Roth, M. T., Gharkholonarehe, N., \& Mumper, R. J. (2013). Pharmacy student engagement, performance, and perception in a flipped satellite classroom. American Journal of Pharmaceutical Education, 77(9): 196.

Montgomery, A. P., Hayward, D. V., Dunn, W., Carbonaro, M., \& Amrhein, C. G. (2015). Blending for student engagement: Lessons learned for MOOCs and beyond. Australasian Journal of Educational Technology, 31(6), 657-670.

Nonaka, I., \& Takeuchi, H. (1995). The knowledge-creating company. New York, NY: Oxford University Press.

Nonaka, I., \& Toyama, R. (2003). The knowledge-creating theory revisited: Knowledge creation as a synthesizing process. Knowledge Management Research \& Practice, l(1), 2-10.

Omotayo, F. O. (2015). Knowledge management as an important tool in organisational management: A review of literature. Library Philosophy and Practice (e-journal), 
Paper 1238.

Papadopoulos, Y., \& Tegos, S. (2012). Using microworlds to introduce programming to novices. In Proceedings of the 2012 16th Panhellenic Conference on Informatics (pp. 180-185). Piraeus, Greece.

Pattnaya, J. (2017). Knowledge management in e-learning a critical analysis. International Journal of Engineering and Computer Science, 6(5), 21528-21533.

Rahman, A. A., Aris, B., Rosli, M. S., Mohamed, H., Abdullah, Z., \& Zaid, N. M. (2015). Significance of preparedness in flipped classroom: Enhancement initiatives for secondary education. Advanced Science Letters, 21(10), 3388-3390.

Rice, J. L., \& Rice, B. S. (2005). The applicability of the SECI model to multiorganisational endeavours: An integrative review. International Journal of Organisational Behaviour, 9(8), 671-682.

Rogalski, J., \& Samurçay, R. (1990). Acquisition of programming knowledge and skills. In J. Hoc, T. Green, R. Samurcay, \& D. Gilmore (Eds.), Psychology of Programming (pp. 157-174). London, UK: Academic Press.

Sahin, A., Cavlazoglu, B., \& Zeytuncu, Y. E. (2015). Flipping a college calculus course: A case study. Educational Technology \& Society, 18(3), 142-152.

Salem, M. I. (2014). The role of universities in building a knowledge-based economy in Saudi Arabia. International Business \& Economics Research Journal, 13(5), 10471056.

Schultz, D., Duffield, S., Rasmussen, S. C., \& Wageman, J. (2014). Effects of the flipped classroom model on student performance for advanced placement high school chemistry students. Journal of Chemical Education, 91(9), 1334-1339.

Shih, J. L, Chuang, C. W., \& Huang, G. J., (2010). An inquiry based mobile learning approach to enhancing social science learning Effectiveness. Educational Technology \& Society, 13(4), 50-62.

Shih, W. L., \& Tsai, C. Y. (2017). Students' perception of a flipped classroom approach to facilitating online project-based learning in marketing research courses. Australasian Journal of Educational Technology, 33(5), 32-49.

Sloman, M. (2007). Making sense of blended learning. Industrial and Commercial Training, 39(6), 315-318.

Sparks, S. D. (2011). Schools "flip" for lesson model promoted by Khan Academy. Education Week, 31(5), 1-14.

Sun, J. C. Y., Wu, Y. T., \& Lee, W. I. (2016). The effect of the flipped classroom approach to OpenCourseWare instruction on students' self-regulation. British Journal of Educational Technology, 48(3), 713-729.

Tatachar, A., Li, F., Gibson, C. M., \& Kominski, C. (2016). Pharmacy students' perception of learning and satisfaction with various active learning exercises. Currents in Pharmacy Teaching and Learning, 8(4), 577-583.

Thai, N. T. T., De Wever, B., \& Valcke, M. (2017). The impact of a flipped classroom design on learning performance in higher education: Looking for the best "blend" of lectures and guiding questions with feedback. Computers \& Education, 107, 113-126.

Thongkoo, K., Panjaburee, P., \& Daungcharone, K. (2017). An inquiry blended SECI model-based learning support approach for promoting perceptions and learning achievement of university students. In Proceedings of the 2017 6th IIAI International Congress on Advanced Applied Informatics (pp. 527-532). Hamamatsu, Japan.

Thongkoo, K., Panjaburee, P., \& Daungcharone, K. (2019). A development of ubiquitous learning support system based on an enhanced inquiry-based learning approach. International Journal of Mobile Learning and Organisation, 13(2), 129-151.

Tucker, B. (2012). The flipped classroom: Online instruction at home frees class time for learning. Education Next, 12(1), 82-83.

Tune, J. D., Sturek, M., \& Basile, D. P. (2013). Flipped classroom model improves 
graduate student performance in cardiovascular, respiratory, and renal physiology. Advances in Physiology Education, 37(4), 316-320.

Wang, F. H. (2017). An exploration of online behaviour engagement and achievement in flipped classroom supported by learning management system. Computers \& Education, 114, 79-91.

Warter-Perez, N., \& Dong, J. (2012). Flipping the classroom: How to embed inquiry and design projects into a digital engineering lecture. In Proceedings of the 2012 ASEE PSW Section Conference. San Luis Obispo, CA.

Wu, H.-K., \& Hsieh, C. E. (2006). Developing sixth grader's inquiry skills to construct explanations in inquiry-based learning environments. International Journal of Science Education, 28(11), 1289-1313.

Yilmaz, R. (2017). Exploring the role of e-learning readiness on student satisfaction and motivation in flipped classroom. Computers in Human Behavior, 70, 251-260.

Zappe, S., Leicht, R., Messner, J., Litzinger, T., \& Lee, H. (2009). "Flipping" the classroom to explore active learning in a large undergraduate course. In Proceedings of the 2009 ASEE Annual Conference and Exposition. New Orleans, LA, USA. 


\section{Appendix I}

Table I

Descriptive statistics

\begin{tabular}{|c|c|c|c|}
\hline \multirow{2}{*}{ Criteria } & \multicolumn{3}{|c|}{ Level of performance } \\
\hline & 3 & 2 & 1 \\
\hline \multicolumn{4}{|l|}{ PHP Programming Skills } \\
\hline $\begin{array}{l}\text { The ability in PHP } \\
\text { programming language } \\
\text { planning and solving } \\
\text { problems from given } \\
\text { proposition (S1) }\end{array}$ & $\begin{array}{l}\text { Knows the PHP } \\
\text { statement that must } \\
\text { be use and can } \\
\text { define variables to } \\
\text { each set of } \\
\text { command }\end{array}$ & $\begin{array}{l}\text { Knows the PHP } \\
\text { statement that must } \\
\text { be use but cannot } \\
\text { define variables to } \\
\text { each set of command }\end{array}$ & $\begin{array}{l}\text { Does not knows the } \\
\text { PHP statement that } \\
\text { must be use but can } \\
\text { define variables to use }\end{array}$ \\
\hline $\begin{array}{l}\text { The capability of student } \\
\text { ability to understand PHP } \\
\text { programming language } \\
\text { structures and make the } \\
\text { program output correctly (S2) }\end{array}$ & $\begin{array}{l}\text { Capable to program } \\
\text { according to PHP } \\
\text { structure and make } \\
\text { the program output } \\
\text { correctly }\end{array}$ & $\begin{array}{l}\text { Capable to program } \\
\text { according to PHP } \\
\text { structure but cannot } \\
\text { make the program } \\
\text { output correctly }\end{array}$ & $\begin{array}{l}\text { Unable to program } \\
\text { according to PHP } \\
\text { structure and cannot } \\
\text { make the program } \\
\text { output correctly }\end{array}$ \\
\hline $\begin{array}{l}\text { The capability to gives advice } \\
\text { in writing PHP programming } \\
\text { language }(\mathrm{S} 3)\end{array}$ & $\begin{array}{l}\text { Capable to give } \\
\text { advice in writing } \\
\text { PHP to creates set } \\
\text { of command in } \\
\text { every point }\end{array}$ & $\begin{array}{l}\text { Capable to give } \\
\text { advice in writing } \\
\text { PHP to create set of } \\
\text { command just in one } \\
\text { point }\end{array}$ & $\begin{array}{l}\text { Unable to gives advice } \\
\text { in writing PHP to } \\
\text { create set of command }\end{array}$ \\
\hline \multicolumn{4}{|l|}{ Code Comprehension } \\
\hline $\begin{array}{l}\text { The understanding of PHP } \\
\text { programming language } \\
\text { structures }(\mathrm{C} 1)\end{array}$ & $\begin{array}{l}\text { Understand the } \\
\text { structures, } \\
\text { command line } \\
\text { writing and PHP } \\
\text { programming } \\
\text { language }\end{array}$ & $\begin{array}{l}\text { Understand the } \\
\text { structure, command } \\
\text { line writing, but does } \\
\text { not understand PHP } \\
\text { programming } \\
\text { language }\end{array}$ & $\begin{array}{l}\text { Don't understand the } \\
\text { structure, command } \\
\text { line writing, but } \\
\text { understand PHP } \\
\text { programming language }\end{array}$ \\
\hline $\begin{array}{l}\text { The understanding of PHP } \\
\text { function code }(\mathrm{C} 2)\end{array}$ & $\begin{array}{l}\text { Understand the } \\
\text { PHP function code } \\
\text { and can choose the } \\
\text { set of command }\end{array}$ & $\begin{array}{l}\text { Understand the PHP } \\
\text { function code but } \\
\text { cannot choose the set } \\
\text { of command }\end{array}$ & $\begin{array}{l}\text { Don't understand the } \\
\text { PHP function code and } \\
\text { cannot choose the set } \\
\text { of command }\end{array}$ \\
\hline $\begin{array}{l}\text { The ability to adapt the } \\
\text { knowledge (C3) }\end{array}$ & $\begin{array}{l}\text { Able to adapt the } \\
\text { knowledge into all } \\
\text { practical learning }\end{array}$ & $\begin{array}{l}\text { Able to adapt the } \\
\text { knowledge into one } \\
\text { practical learning } \\
\text { only }\end{array}$ & $\begin{array}{l}\text { Able to adapt the } \\
\text { knowledge into } \\
\text { practical learning, but } \\
\text { unable to answer } \\
\text { correctly }\end{array}$ \\
\hline
\end{tabular}

